\title{
12. History, oral history, and memoriation in native title
}

\section{James F. Weiner}

In the realm of native title, the distinction between 'traditional' and 'historical' people is one that is given official acknowledgement both by the courts of Australia and by Aboriginal people themselves. In the current guidelines for the production of native title connection reports (at least as construed by the State of Queensland) the anthropologist is required to address him/herself to the contrastive histories of such traditional and historical peoples - those who can demonstrate a connection to country that predates settlement, and those whose connection was established afterwards.

But the terminology here is anthropologically confusing. Would someone with a 'traditional' connection to land not also have a history of occupation of it? And would a 'historical' person have jettisoned any connection to a pre-colonial cultural world just because he/she is living on country other than that to which he/she was traditionally entitled? Anthropologists therefore have for the most part consistently criticised such a distinction. All anthropologists working in such places as the Pilbara, the Gulf country and adjacent Cape York and the eastern Northern Territory, insist that 'historical' relations to country are impossible to disentangle from ... from what? What would we call such relations to country that we did not admit had a historical component?

Part of the difficulty in answering this question, or a source of the inability of history and anthropology to achieve an effective synergy, is the current rhetoric of Aboriginality itself. The requirements of the Native Title Act 1993 (Cwlth), at least since the Yorta Yorta native title hearing in the Federal and High Courts, have obliged Aboriginal claimants to prove that they have retained traditional law and custom in some form. While admitting that such law and custom can undergo change over time, it must remain functionally and structurally recognisable as such. However, Aboriginal claims to the perdurability of the Law, its alleged unchangingness (see Sansom 2006), provide a narrower channel within which the anthropologist and historian can interpret the effects of event upon the structure of Aboriginal practices and world views. (It is hoped, of course, that both would see such attestations as themselves culturally-inflected utterances, generated from within a specific landscape of cultural, social and political positions).

Another difficulty, related to the one above, is that the various State Native Title Services' distinction between 'traditional' and 'historical' reflects in some important way - though with some distortion - the conventional disciplinary 
separation within Australian anthropology departments between 'traditional' and 'contemporary' Aboriginal society as distinct lecture courses - a regime in which status, approbation and the comfort of carrying out what Kuhn called 'normal science' accrued largely to postgraduates crafting degrees within the former and not the latter. It is hardly surprising that State and Federal legal departments, searching for what anthropologists had to say about Aboriginal society, found many examples from the former and far fewer from the latter.

But perhaps a more serious difficulty is that such a distinction has generated a corresponding professional division of labour between anthropologists and historians, a division of labour now given conventional sanction by the courts for the most part.

In the native title cases I have been involved in over the past few years, I have encountered the following:

1. A consultant historian is engaged to write a 'historical' report on the claim group for which an anthropologist is writing the connection report. The historical report is a compilation of passages gleaned from the State Aboriginal Archives, evidently generated by running a computer search on the names and surnames of the component claimant families.

2. Instead of an 'anthropological' report, an 'oral historian' - with no university qualifications in any discipline - instead produced several hundred pages of unedited interview transcript as 'connection material'.

3. An anthropologist confined him/herself to the elucidation of kinship and social organisational principles and other cultural 'rules', while a professional historian wrote a much longer and more detailed history of occupation of the claim area.

In the Karajarri claim, Geoff Bagshaw's monograph (2003) deals with the cosmogonic, mythological, and ritual foundations of Karajarri connection to country, while anthropologist Sarah Yu evidently authored a separate report dealing with history of occupation and the catalogue of physical activities constitutive of native title that members of the Karajarri claimant group have engaged in and presently engage in (Bagshaw 2003: 35). What is undermined by this strategy is the ability to assess the historical dimensions of a symbolically-constituted cosmology. This bifurcation of social science analysis prevents us from considering the cosmological, ritual and mythological domain of the Karajarri as a historically generated adaptation - and hence reinforces all of the negative stereotypes that have been made of anthropologists.

Such a distinction is in social science terms insupportable and factitious. In the first De Rose FC case, consider what O'Loughlin J concluded were the principles by which an Aboriginal person asserted the status of nguraritja, 'custodian' of a site or area. At 922, he affirmed the anthropologist Craig Elliott's account (at 
349) that a person can become nguraritja through birth, long-time physical association, ancestral connection or knowledge of the area, and recognition by other nguraritja. The Aboriginal witnesses' statements made it clear that the applicants individually made use of one or more of these principles in different combinations to assert their status as nguraritja. These ways of achieving the status of nguraritja are completely historically constituted - although they occur against the background of cultural principles relating people and sites in general ways, they are contingent upon the particularities of personal sojourns in space and time. Nguraritja is biographically constituted even as it embodies the primary spiritual relation between person and place. What then is the substantive difference between these historically constituted attachments to place and the ones that other Indigenous people have achieved to various sites and pastoral properties throughout Australia?

In this brief paper, I am drawing attention to two analytic separations that have been engendered by the native title process. One is the contrast between society viewed as a static bundle of structural and normative laws and principles, and society as a historically-constituted community of persons associated both temporally and spatially. This has led to the recognition of distinct anthropological and historical contributions to the demonstration of proof of native title, a distinction that has been more detrimental to anthropology than to history.

The second analytic separation is analogous, in that it has to do with the separation of anthropology and history, but has been wrought by disciplinary competition and revision rather than as an effect of the judicial interpretations of social science boundaries. Separating anthropology's commitment to the structural and structural-functional from its historical dimension leads to an overly particularistic history. Removing the social and cultural from a consideration of the historical production of the subject has allowed history to insert its own version of subjectivity, the self as a node of memoriation, rather than as an inter-subjective, culturally constituted self.

Both of these distinctions are products of the devaluation of the structural and the cultural in Aboriginal anthropology, and both are responses, in different ways, to the dilemma of drawing attention to the phenomenon of 'loss of culture' in many of Australia's Aboriginal communities in settled Australia. The judicial interpretation of native title has forced anthropologists to make judgements on the degree of retention of 'traditional law and custom' among contemporary Aboriginal communities. While some anthropologists may be hesitant to discuss the possibility of loss of culture, it is more difficult to countenance the loss of history or memory, which then becomes the safer academic terrain upon which to confront 20th century Aboriginal continuity. 


\section{History vs anthropology}

As Geertz suggested, what has helped undermine the difference in subject matter between historians and anthropologists 'has been a change in the ecology of learning that has driven historians and anthropologists, like so many migrant geese, on to one another's territories' (2000: 121). There is nowhere in the world these days (nor I suspect for most of the last 100 years) where an indigenous village or community has been left out of the flow of global events and influences, so that such history becomes at least a necessary prelude to the identification of more conventional anthropological problems. ${ }^{1}$ And historians, again for longer than we would care to admit, have known that places like Indonesia, West Africa, and Polynesia have fully their own complement of documentary sources, sources that allow the historian to write about these places in the same way they have written about European ones. 'Culture' is certainly a way of speaking about the varieties of coherence of human social life, but it emerges within a historically construed horizon of time and place, not apart from it.

So, anthropology is and was already a historicised mode of social analysis - social formations unfold through time and therefore proper anthropological inquiry in the field is a process that has to be situated diachronically, that is, across an interval of time. There have been dominant modes of anthropological analysis that have stressed the importance of synchronic analysis (that is, confined to a single moment in time) - for example, structural analysis, structural-functionalism and certain forms of symbolic anthropology. These methodologies illuminate the important aspects of systemicness that are part of all cultural forms. But anthropology also acknowledges that cultures and social systems make themselves visible as temporally-constituted social phenomena.

Human cultures everywhere thus recognise the historical and biographical dimensions of human life. The anthropologist Marshall Sahlins (1981) reminded us that social and cultural structures are reproduced through events, an approach that critiques the methods employed in allocating different historical and anthropological tasks in the connection report process. He went on to suggest that events of major culture contact had the power to more sharply illuminate the structures of society and its reproduction - for all parties to the contact.

But this alone does not make history and anthropology difficult to distinguish today. Even as Sahlins was arguing for a more historicised structural anthropology, anthropology has more recently thoroughly disengaged itself from any structuralism, disengaged itself from the notion that a culture is (or

\footnotetext{
1 This perception itself has a very long anthropological life. It was Evans-Pritchard's ground-breaking study of the Sanusi cult of Cyrenaica, that demonstrated, according to Cohn, 'the process by which a lineage-based society developed centralized political roles and institutions' (1968: 442). Cohn (ibid.) termed it a 'model for the study of the process of internal structural change ... under the impact of foreign rule.'
} 
ever was) a coherent and systemic entity that was susceptible to description as formulaic or as rule-governed - a complaint also levelled at anthropology by Sutton (see for example Pannell and Vachon 2001). Whereas Lévi-Strauss once confidently spoke of the 'death of the subject', we have recently seen the subject and subjectivity become the centre of social analysis. Subjectivity has become largely an effect of narrativity, a reflection, perhaps, of the rise of textualism generally as a model for social and psychological life.

If the self is today largely a narrative project, it becomes more closely associated with other textual projects - such as mythopoeia. History and anthropology have become increasingly harder to draw, not because there has been any significant unification of social science theory - although others might wish to argue otherwise - but because, I think, of the increasing acceptance of the project of mythopoeia in western public life. As Faubion (1993: 44) put it: 'If, in the last two decades, history has itself become anthropologically indefinite, that is in part because the lines between the reproduction and invention of tradition, between mnemonics and conjuration, and between myth and historia' have grown increasingly less distinguishable. As Faubion (ibid.) suggests, our current attitude towards the Human Condition 'is nostalgist even when at its most futurist and has virtually sacralized history, even if in sacralizing and making an essence of it, it has also done violence to it ...'. In other words, anthropology jettisoned structuralism, and history jettisoned the event; the very conjunctural ground that Sahlins tried to stake out. Having abandoned this ground, the two disciplines found themselves competing over the right to authorise a version of memoriology.

\section{History, narrative, ethnohistory}

The dangers of memoriology lead me to my final observation on the methodological problems generated by native title for the social sciences. For one of the ways in which contemporary social science has repaired the lack of indigenous voices in conventional history is to embark on a wholesale project of oral history. Oral history has become the methodological substitute for the almost complete absence of reliable records of the words, theories and analyses of Aboriginal social action at the threshold of colonisation: 'Ethnohistory might address the native reception of events. It made plain that peoples purportedly without history had histories after all. It occasionally found in their oral tradition the glimmer of some crude art of memory' (Faubion 1993: 42).

But Faubion never confused this with the art of historia. The contrast that has emerged within native title research in recent years is not so much between the disciplines of history and anthropology — for as I have suggested such was always a factitious opposition within anthropology in the first place - as between the objective validity of the documentary record and claimants' counterposed 'oral history'. 'Oral history' is not an exclusively anthropological methodology, and never was, even though methodologically it was not differentiated from some 
anthropological modes of questioning. But to call claimants' self-narratives 'oral history' is to conceal the fact that it is not history as such - it is a congealed form of memoriation. Much of the 'oral history' I read has been obtained by people who evidently see memory as a form of text and who 'treat memory as a set of documents that happen to be in people's heads rather than in the Public Records Office' (Fentress and Wickham 1992: 2).

From this perspective, memoriation brings a view of history into an already-defined and accepted history of the subject. It commonly becomes a story about how the subject has achieved an identity and subject-position, rather than constitutes a 'history of the person' per se. The sociologist Stuart Hall writes, however, that identities are themselves 'the names we give to the different ways we are positioned by, and position ourselves in, the narratives of the past' (quoted without citation in Huyssen 1995: 1). In other words, identities emerge as an effect of a self located in and acting within a social field, a field which is temporal, spatial and human simultaneously. Aboriginal people's construction of memory and oral history is an identity-building practice, fully culturally constituted. It is not disengaged from other cultural practices, such as that of being a native title claimant, but it is insufficiently accounted for in the current repertoire of 'laws and customs'.

As social processes themselves, the human acts of recalling and remembering are selective and interpretational processes and in important methodological respects distinct from the historian's task of constructing an objective account of the past. Historians Christine Choo and Margaret O'Connell thus say: 'Historical narrative goes beyond chronology because it imposes a discursive form on the events; transforming the events into a story, it gives meaning to the events by presenting the events, agents and agencies as elements of identifiable story types' (2000: 2; emphasis added). If these stories are subjective in their origin and meaning, then they are contiguous with other social phenomena that constitute the community and are therefore within the domain of anthropological analysis. By the same token, such stories that a community authors for itself are not a preferred alternative to other historical accounts, or to the record of documented events. They themselves are another culturally-constructed gloss on such events and documents, and it is, as both Sahlins and Sutton concur (e.g. Sutton 2003: 19) in the mutually constitutive relation between event and its human apperception that cultural accounts are forged.

But the contrast between 'objective history' and 'oral or ethno-history' is itself a highly political one, and is used to deliberately polarise the Aboriginal and non-Indigenous positions in the national debate on Indigeneity and Indigenous rights. So I return to a consideration of the way the rhetoric of Aboriginal and non-Aboriginal self-makings, and the attempts on both sides to maintain their epistemological divide via appeals to 'tradition' and 'history', have contoured 
disciplinarity in native title. I make two observations, one about history and the other about culture.

First, the effective contrast is between a previous 'official' colonial history, in which a strong mythographic component is apparent, and a history which seeks, through an appreciation of the course of a total social world, to re-insert previously invisible persons, classes, races and occupants of that colonial world, an approach made famous by E. P. Thompson in his landmark history of the English working class. Anthropologist Jonathan Hill has used the term ethnogenesis to describe 'peoples' simultaneously cultural and political struggles to create enduring identities in general contexts of radical change and discontinuity' (1996: 1). ${ }^{2}$ Its investigation is founded in 'historical approaches to culture as an ongoing process of conflict and struggle over a people's existence and their positioning within and against a general history of domination' (ibid.).

But a historical anthropology of the conjuncture between indigenous and non-indigenous histories is where a suitably defensible anthropological account of connection should start (see for example Merlan 1998). The anthropological sensibility in this approach is admirably expressed by Sutton's forthright assessment of pastoralism as 'the form of colonisation most compatible with the maintenance of traditional Aboriginal connections to land' (2003: 35). Not only did the pastoral industry itself develop a requirement for permanent seasonal Aboriginal labour, Aboriginal forms of subsistence ensured that they remained on properties during the wet season of work lay-off - Sutton thus remarks, 'the viability of the granted leases was in some measure enhanced by, if not dependent on, the maintenance of Aboriginal foraging' (2003: 33). The methodological implications of this observation are also clearly understood by Sutton: 'it is the lawyers' chronologies of official tenure changes, and the anthropologists' diachronic accounts of indigenous laws and customs giving rise to customary rights and interests in land and waters, that form the crucial historical evidence' (2004: 4).

The second point I want to make concerns the restricted field in which we are more or less obliged to locate the evidence for 'the history of connection', and the manner in which we fail to distinguish between discursive and praxical connections to a life world. In settled Australia, 'connection to country' lies chiefly in knowledge of past activities, and it is this knowledge that is transmitted, rather than the repertoire of subsistence skills per se. Further, in settled Australia, much evidence on behalf of native title claims is elicited from informants in their houses, not on country. Anthropologically this produces an attenuated and weakened account of social process, since the interviewer is not

2 Jones and Hill-Burnett (1982, cited in Beckett 1994) used the term 'ethnogenesis' in the Aboriginal Australian context in 1982, defining it as "the process whereby a "common culture" comes about and the manner by which it is defined'. 
observing the social practice of story-telling and narration among group members, but is merely subjecting the informant to a series of questions that itself does not derive dialectically from the observation of social action at all, or does so in an extremely artificial and factitious context. Many native title anthropologists consequently become oriented towards what their interlocutors were able to tell them and insufficiently attuned to the way they behave in a culturally-patterned way. I am not disparaging 'oral history' as such. We can characterise Aboriginal society as an 'orally' rather than 'literarily' based culture - but this should orient us towards a description of the social practices and behaviours by which they transmit and construct knowledge among themselves by way of speech, ${ }^{3}$ rather than indiscriminately to any utterance an Aboriginal person produces, especially in highly-polarised intercultural encounters among anthropologists, lawyers, NTRB personnel and claimants. It is therefore not simply a question about how much or how little people know, but of obtaining an anthropologically respectable account of how such accounts are transmitted and the role of such transmission in current Aboriginal cultural practice.

Unfortunately, anthropologists and other native title researchers have neither the time nor the resources for the kind of participant-observation - a cornerstone of anthropological methodology - that would lead to a description of the social practice of narrative and oral communication. Paradoxically, although the architects of current native title interpretation insist on the historical verifiability of accounts of connection to country, they have been unable to infer from such a demand the anthropological requirement of observation across and within a temporal interval. Without this temporal dimension, however, we can achieve no real anthropological understanding of how society is constituted normatively, for we are unable to construe the social work of interpretation through which people reconcile human behaviour with its idealised rule-governed portrait. Such integral features of anthropological theory and methodology are so far considerably beyond the capacity of legal practitioners to turn into guidelines for practice. In the meantime, anthropology on behalf of native title will be able to bring only a denatured version of its own analysis to bear on the topic.

\footnotetext{
${ }^{3}$ In settled Australia where the transmission of pre-contact Aboriginal cultural and linguistic practices has been severely impaired by dislocation, removal, migration and other factors, many Aboriginal families rely heavily on existing documentary evidence in order to learn about their predecessors' life histories, their places of habitation, their culture and their language. Collections of such documentary evidence become resources that are invoked, publicly shown, deliberately withheld, tactically alluded to, and so forth, in confrontations between Aborigines and non-Aborigines, and between disputing groups of Aborigines themselves.
} 


\section{References}

Bagshaw, G. 2003. The Karajarri Claim: a Case-Study in Native Title Anthropology, Oceania Monograph No. 53.

Beckett, J. (ed.) 1994. Past and Present: the Construction of Aboriginality, Aboriginal Studies Press, Canberra.

Choo, C. and O'Connell, M. 2000. 'Historical narrative and proof of native title', in Land, Rights, Laws: Issues in Native Title, 3 (2), (unpaginated), Native Title Research Unit, Australian Institute of Aboriginal and Torres Strait Islander Studies, Canberra, available as $<$ http://ntru.aiatsis.gov.au/ntpapers/IPv2n3.pdf >.

Cohn, B. 1968. 'Ethnohistory', in D. Sills (ed.), International Encyclopedia of the Social Sciences, Macmillan, New York, pp. 440-8.

Faubion, J. 1993. 'History in anthropology', Annual Review of Anthropology, 22: 35-54.

Fentress, J. and Wickham, C. 1992. Social Memory, Blackwell, Oxford.

Geertz, C. 2000. Available Light: Anthropological Reflections on Philosophical Topics, Princeton University Press, Princeton.

Hill, J. (ed.) 1988. Rethinking History and Myth: Indigenous South American Perspectives on the Past, University of Illinois Press, Urbana.

Huyssen, A. 1995. Twilight Memories: Marking Time in a Culture of Amnesia, Routledge, London.

Jones D. and Hill-Burnett J. 1982. 'The political context of ethnogenesis: an Australian example', in M. C. Howard (ed.), Aboriginal Power in Australian Society. University of Queensland Press, St. Lucia.

Merlan, F. 1998. Caging the Rainbow: Places, Politics and Aborigines in a North Australian Town, University of Hawai'i Press, Honolulu.

Pannell, S. and Vachon, D. 2001. 'Notes and queries in the native title era', The Australian Journal of Anthropology, 12: 238-44.

Sahlins, M. 1981. Historical Metaphors and Mythical Realities, University of Michigan Press, Ann Arbor.

Sansom, B. 2006. 'The brief reach of history and the limitation of recall in traditional Aboriginal societies and cultures', Oceania, 76 (2): 150-72.

Sutton, P. 2003. Native Title in Australia: An Ethnographic Perspective, Cambridge University Press, Cambridge.

Sutton, P. 2004. 'Social scientists and native title cases in Australia', General Anthropology (Bulletin of the General Anthropology Division of the AAA), 11 (1): 1-4. 